\title{
Correction to: What's in a Name? The Occupational Identity of Conservation and Natural Resource Oriented Law Enforcement Agencies
}

\author{
Ryan Patten ${ }^{1} \cdot$ Matthew S. Crow $^{2} \cdot$ Tara O'Connor Shelley $^{3}$ \\ Published online: 18 April 2020 \\ (C) Southern Criminal Justice Association 2020
}

\section{Correction to: Am J Crim Just (2015) 40:750-764 https://doi.org/10.1007/s12103-014-9286-y}

The authors of "What's in a Name? The Occupational Identity of Conservation and Natural Resource Oriented Law Enforcement Agencies," published in 2015, volume 40, issue 4, pp. 750-764, recently uncovered coding errors in their data, which resulted in an inaccurate description of the Specialized Training variable and misreporting the findings for the Specialized Training and Education variables. The description of the Specialized Training variable should have stated the variable measures whether organizations required significant specialized fish and wildlife training in addition to a general law enforcement academy. The findings should have indicated that $21(42 \%)$ agencies required such specialized training. For Education, the findings should have indicated that $23(46 \%)$ of the agencies only required a high school diploma or GED, twelve (24\%) required an associate's degree, and $15(30 \%)$ required a bachelor's degree. By region, in the Northeast, two states required specialized training, five high

The online version of the original article can be found at https://doi.org/10.1007/s12103-014-9286-y

Ryan Patten

rpatten@csuchico.edu

Matthew S. Crow

mcrow@uwf.edu

Tara O’Connor Shelley

SHELLEY@tarleton.edu

1 California State University, Chico, 400 W. First St, Chico, CA 95929, USA

2 Department of Criminology and Criminal Justice, University of West Florida, Pensacola, FL, USA

3 Department of Criminal Justice, School of Criminology, Criminal Justice, and Strategic Studies, Tarleton State University, Fort Worth, TX, USA 
school/GED, two an associate's degree, and two a bachelor's degree; in the Midwest, seven states required specialized training, three high school/GED, five an associate's degree, and four a bachelor's degree; in the South, seven states required specialized training, ten high school/GED, three an associate's degree, and three a bachelor's degree; in the West, five states required specialized training, five high school/GED, two an associate's degree, and six a bachelor's degree. 